Review Article

\title{
Design Multistage External Gear Pumps for Dry Sump Systems: Methodology and Application
}

\author{
Davide Guerra (D), Marco Polastri $\left(\mathbb{D}\right.$, Mattia Battarra ${ }^{(D)}$, Alessio Suman $(\mathbb{D}$, \\ Emiliano Mucchi $(\mathbb{D}$, and Michele Pinelli \\ Department of Engineering, University of Ferrara, Ferrara 44122, Italy \\ Correspondence should be addressed to Emiliano Mucchi; emiliano.mucchi@unife.it
}

Received 29 September 2020; Revised 3 February 2021; Accepted 27 February 2021; Published 10 March 2021

Academic Editor: Mohamed Shaat

Copyright (c) 2021 Davide Guerra et al. This is an open access article distributed under the Creative Commons Attribution License, which permits unrestricted use, distribution, and reproduction in any medium, provided the original work is properly cited.

\begin{abstract}
Thanks to their manufacturing simplicity, robustness, and consolidated design knowledge, external gear pumps are widely adopted in the automotive fields. With the purpose of leading the design procedure of these positive displacement machines, within this work, the authors integrate in a comprehensive tool the salient equations adopted for the design of the major gear pump features. The presented procedure is devoted to the design of multistage external gear pumps characterized by a singular floating driving shaft supported by fluid-dynamic journal bearings. Focusing the attention on the procedure flexibility, it has been structured in three iterative calculation phases. The core section of the methodology concerns the geometrical design of the involute gear tooth profile. It is oriented to ensure a proper volumetric displacement while complying with the space requirement and the tooth manufacturing limitations. Thus, through the analytical pressure loads estimation combined with the operational parameters, the second calculation step provides the design of the driving shaft and the relevant dimensions of the journal bearings. Finally, by means of a power loss approach, the third macrosection of the procedure leads to estimating the clearances between gear tip and housing. The potentials of the methodology are exposed by describing its applications to a case study of multistage gear pump employed in the dry sump lubrication system of an automotive heavy-duty engine. Each calculation step application is outlined with reference to the proposed analytical formulation and the results of the parameters calibration are presented. Within this context, the procedure is assessed by means of a CFD analysis. The results highlight the accuracy of the methodology on the estimation of the required delivery flow rate. Aside from being accurate, flexible, and reliable, the procedure stands out for being an innovative tool within the multistage gear pump framework.
\end{abstract}

\section{Introduction}

Reliability and robustness are the most recognized features of external gear pumps which have promoted the wide diffusion of these machines in a great variety of fields of the mechanical industry. With the purpose of answering to the requests of constant improvement of the pump's performance, the development of new studies, in terms of mechanical or fluid-dynamic efficiency, as well as in terms of vibroacoustic characterization, is increasingly encouraged. Over the years, several studies have been carried out for the development of simulation procedures which aim to describe the fluid-dynamic behavior of the pumps.
A fundamental contribute to the research was provided by Mancó and Nervegna in [1], where an experimental methodology for the detection of the pressure within gear tooth spaces was proposed. The successful measurements were carried out as a validation method for the lumped parameters model proposed by the same authors in [2]. Since the validation processes of numerical models by means of experimental tests have been adopted, further development of the modeling strategies has permitted constant improving of the simulation models.

The works presented by Mucchi et al. in [3,4] provide a nonlinear mathematical model devoted to the calculation of the gear eccentricity. The salient aspects considered within the study are pressure loads, meshing forces, and bearing 
reactions. The comparison between simulation and experimental trials has led to the assessment of the model. Later, as presented in [5], the lumped parameters model has been developed to focus on the features of the flow during the meshing process. Phenomena such as local pressure peaks and cavitation phenomena have been detected and characterized. In addition, the model provides a methodology for the prediction of the gear axes micromotion and for the casing wear due to the break-in process. The relevance of the hydraulic efficiency of gear pumps has been considered as a core argument in [6,7]. In [6], the authors present a mathematical model focused on the evaluation of the hydromechanical efficiency on external gear machines. Flow rate losses arising from internal clearances of the pump (tooth tip clearance, journal bearings clearance, and lateral gap) and the mechanical losses resulting from the meshing process and from friction phenomena have been investigated. Furthermore, in [7], a technique for investigating the influence of gear manufacturing errors related to gear conicity on the volumetric efficiency is proposed. Within the same framework, in [8], the authors analyzed the influence of manufacturing tolerances on tooth tip clearances and bearing clearances on the pump efficiency.

The effects of gear manufacturing and assembly errors on meshing loads have been deeply investigated by the authors in [9]. In addition, in [10], the connection between the stiffness of floating supports and the meshing forces has been extensively surveyed.

In the scientific literature, the study of the behavior of multistage pump is lightly discussed. The topic has been investigated in [11], where a former work of the authors [12] has been integrated in a lumped parameters model. The implemented model has been addressed by CFD analyses carried out in parallel and, finally, validated by dedicated experimental campaigns.

Within this context, the aim of the present work is to detail the calculation steps of a multistage gear pump design in a flexible and robust procedure. The exposed methodology has been structured with the purpose of driving the design procedure with the choice and calibration of a limited number of input parameters. The main outcomes of the presented design procedure concern the detailed gear-pair geometry, which includes also information regarding the rack cutter profile, the maximum allowable width of the relief grooves, as well as the gear-pair center position, and the estimation of the gear stock allowance. It is worth pointing out that the geometrical design of the gears concerns traditional enveloped tooth profiles. It is based on the analytical equations presented in [13] and integrated with the pump displacement calculation presented in [14]. Moreover, the calculation is carried out as an iterative procedure within which the gear pair could be tailored to meet the established space requirement and functioning constraints through the manual calibration of the input parameters. In addition, not only does the proposed procedure provide the geometrical characterization of the gear pump, but also it deals with its structural design. In this framework, the method provides the chance to select the number of pump stages, calculate the torques and the pressure loads and, consequently, determine support loads. Furthermore, the main pump clearances, addressed by [15], and the design of the journal bearings have been implemented by correlating them to the tooth geometry, the estimated loads, and the working condition parameters. The presented procedure has been applied to a case study constituted by a three-stage gear pump, where the flexibility of the method has been proved. With the purpose of ascertaining the performances of the designed pump, a CFD analysis has been performed with reference to the models reported in [16] and [17]. The results show the achievement of the target performances, validating the calculation methodology and proving its robustness and accuracy. Despite the availability of a wide range of studies and theoretical dissertations describing the phenomena involved in the pump operating behavior, these approaches are always proposed as single technical insights and rarely collected in an integrated context. Based on the authors' experience, there is a lack in the specialized literature as regards the definition of a comprehensive procedure that allows obtaining the whole pump geometry, starting from the design specifications and the space and performance constraints.

In the first section of this manuscript, the design procedure is presented detailing the analytical formulation at the basis of the methodology. The second section concerns the development of a case study following the whole analytical procedure including the principles of the CFD analysis and the assessment of the simulations results. Finally, the last section is devoted to concluding remarks.

\section{Design Strategy and Calculation Procedure}

In the current section, the analytical formulae, which constitute the structure of the presented design methodology, are exposed and described. The procedure has been tailored on a multistage gear pump. Each pump stage is assumed to adopt the same pair of spur gears and to be driven by a single floating driving shaft. Its layout varies according to the number of stages, which represents fundamental input data for the procedure. Moreover, within the framework of the methodology, the driving shaft is assumed to be supported by journal bearings. The layout of an $N$ stages pump and its driving shaft has been depicted in Figure 1 .

The design strategy implemented in this work has been structured in three iterative calculation phases, described in the following sections. Figure 2 illustrates the workflow of the procedure and the iteration scheme of each calculation phase. The calculation scheme presented in the first section is described in the red highlighted part of Figure 2, whereas the green highlighted part illustrates the calculation scheme presented in the second section. The calculation scheme of the third section is illustrated in the blue highlighted part.

Section 1 focuses on the attention on the calculation of a proper tooth profile that meets the space requirements limitation while ensuring the expected displacement. The gear design phase ends with the pregrinding profile calculation, which leads to calculating the real rack cutter data. 


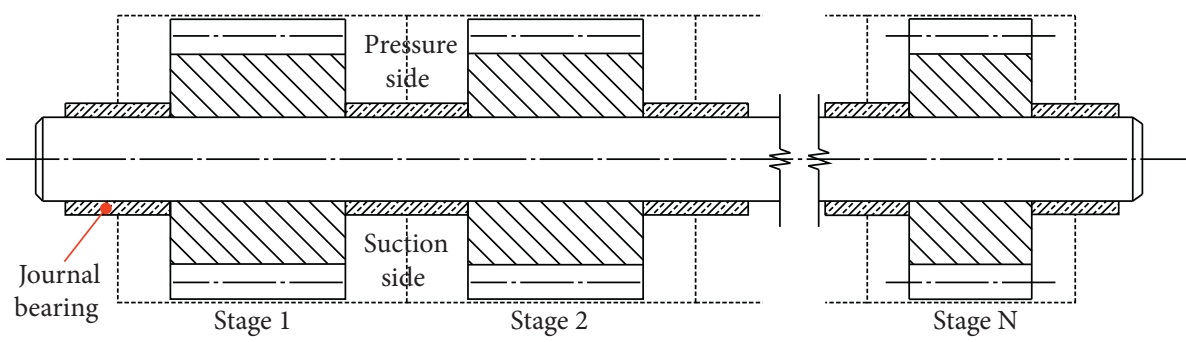

Figure 1: $N$-stages pump layout.

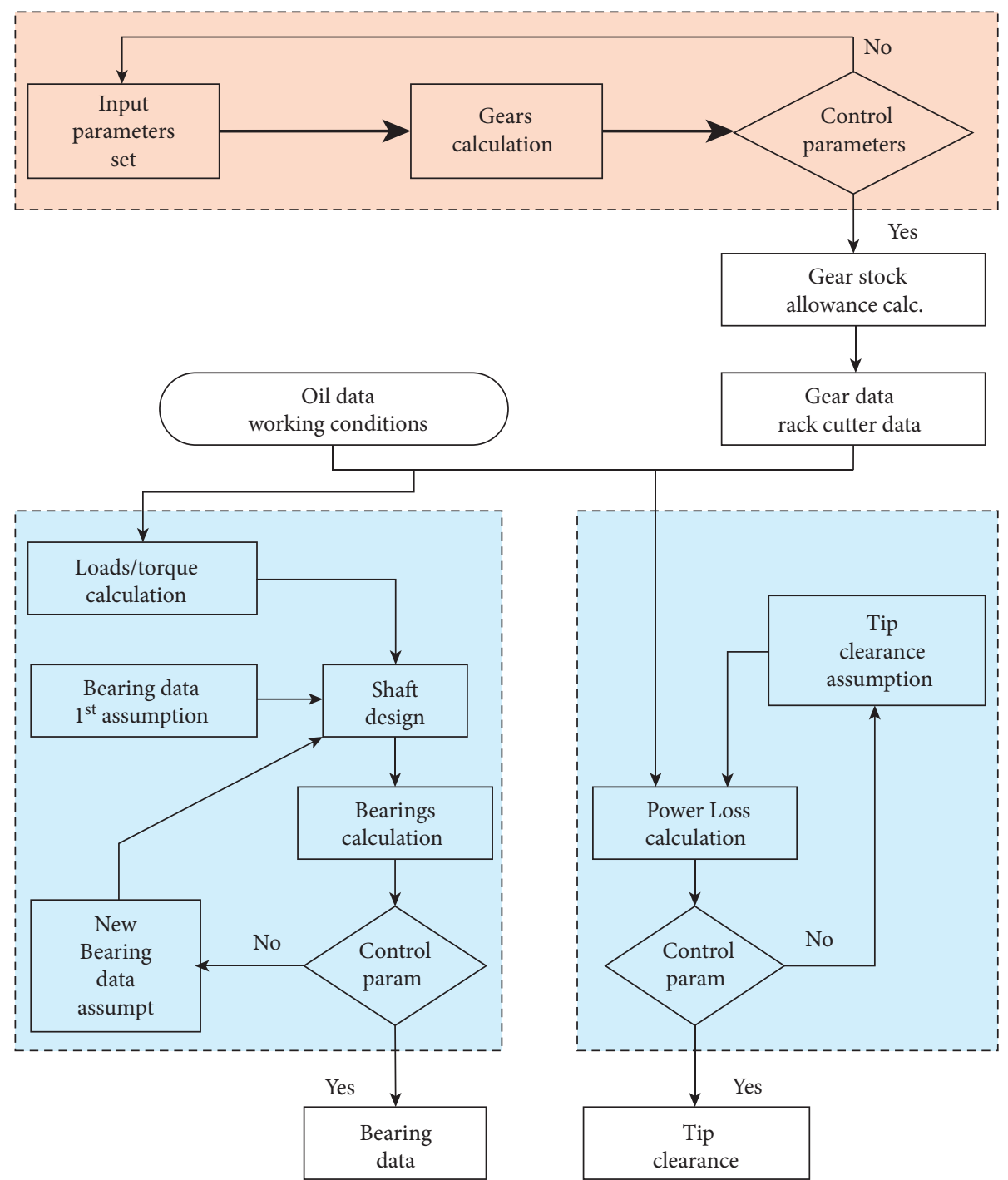

FIGURE 2: Design procedure workflow.

Consequently, Section 2 presents the calculation of torque and loads acting on the driving shaft, its structural design, and the design methodology for the journal bearings. Finally, Section 3 is dedicated to the description of the design methodology for the casing radial gap.

2.1. Geometrical Design of Gears. The first calculation step of the geometrical design phase leads to obtaining a draft gear pair. By means of geometrical input parameters $m, z, \alpha, x$, $a d_{T}, h_{T}$, and $\varphi_{T}$, the geometry of the rack cutter tool is defined and, thereafter, the first output parameters set is generated. Equations from (1) to (5) form the first group of analytical equations of the first calculation step.

$$
\begin{aligned}
I & =D_{\text {pitch }}=m \cdot z, \\
D_{\text {base }} & =D_{\text {pitch }} \cdot \cos \alpha,
\end{aligned}
$$




$$
\begin{aligned}
D_{r} & =D_{\text {pitch }}-2 \cdot\left(a d_{T}-x\right) \\
t_{\text {pitch }} & =\frac{\pi m}{2}+2 \cdot x \cdot \tan \alpha, \\
D_{\text {tip }, \text { lim }} & =D_{\text {pitch }}+\left(h_{T}-a d_{T}\right)+x .
\end{aligned}
$$

Limit tip diameter, calculated in equation (5), represents the upper limit for the tip diameter of the gears. The choice of a proper value introduces the second calculation step, where the input parameters $I_{\mathrm{op}}, D_{\text {tip }}$, and B allow completing the calculation of the draft gear pair. By defining the operative pressure angle $\alpha_{\text {op }}$,

$$
\alpha_{\mathrm{op}}=\cos ^{-1}\left(\frac{I \cos \alpha}{I_{\mathrm{op}}}\right)
$$

operative pitch diameter $D_{\text {pitch,op }}$ is achieved:

$$
D_{\text {pitch,op }}=\left(\frac{\cos \alpha}{\cos \alpha_{\text {op }}}\right) D_{\text {pitch }} \text {, }
$$

and, thus, tooth thickness at operative pitch diameter $t_{\text {pitch,op }}$ is calculated:

$$
t_{\text {pitch }, \text { op }}=\left(\frac{t_{\text {pitch }}}{D_{\text {pitch }}}+\operatorname{inv}(\alpha)-\operatorname{inv}\left(\alpha_{\text {op }}\right)\right) D_{\text {pitch,op }}
$$

and tip pressure angle $\alpha_{\text {tip }}$ is calculated as

$$
\alpha_{\text {tip }}=\cos ^{-1}\left(\frac{D_{\text {tip }} \cos \alpha}{D_{\text {pitch }}}\right)
$$

moreover, clearance at root diameter $\delta_{r}$ is defined as

$$
\delta_{r}=I_{\mathrm{op}}-\frac{1}{2}\left(D_{r}+D_{\text {tip }}\right) \text {. }
$$

In order to achieve the target performances, the values of some calculated output parameters have to stick to fixed limit values. These parameters play the role of control parameters and lead to orienting the choice of the input parameters. Throughout the current phase, control parameters are calculated in addition to the output parameters already presented.

Pump displacement $C c_{\text {lim }}$ is a control parameter set out according to the target delivery flow rate. Its value is calculated as

$$
C c_{\lim }=\frac{C c_{\mathrm{tar}}}{\eta_{v} *}
$$

where $C c_{\mathrm{tar}}$ is the target displacement provided as constraint data in the early phase of the design and $\eta_{v} *$ is the assumed volumetric efficiency of the pump.

The formulation exposed in equation (12) relies on [14] and allows calculating the design displacement for the input parameters set:

$$
C c_{\text {des }}=2 \pi B\left[\left(\frac{D_{\text {tip }}}{2}\right)^{2}-\left(\frac{D_{\text {pitch,op }}}{2}\right)^{2} \cdot\left(1+\frac{1}{3} \cdot\left(\frac{\pi \cos \alpha_{\text {op }}}{z}\right)^{2}\right)\right]
$$

and, thus, the admissible error on the control parameter $C c_{\text {lim }}$ has to be assumed for the assessment of calculated displacement $C c_{\text {des }}$.

The total width limit $w_{\text {lim }}$ is a control parameter imposed in order to limit the space requirement of the gearing. Equation (13) shows the analytical formula for total width calculation and the comparison related to the limit value as well:

$$
w=I_{\text {op }}+D_{\text {tip }}\left(<w_{\text {lim }}\right)
$$

Furthermore, thickness of the teeth $\left(t_{\text {tip }}\right)$ is calculated as

$$
t_{\text {tip }}=\left(\frac{t_{\text {pitch }}}{D_{\text {pitch }}}+\operatorname{inv}(\alpha)-\operatorname{inv}\left(\alpha_{\text {tip }}\right)\right) D_{\text {tip }}\left(>t_{\text {tip }, \text { lim }}\right)
$$

where $t_{\text {tip,lim }}$ is assumed to guarantee the gear manufacturability.

Backlash $b$ calculation is provided by

$$
b=\left(\frac{\pi D_{\text {pitch,op }}}{z}-2 t_{\text {pitch,op }}\right) \frac{D_{\text {pitch }} \cos \alpha}{D_{\text {pitch,op }}}\left(>b_{\text {lim }}\right) \text {. }
$$

where backlash limit value $b_{\text {lim }}$ is assumed from good practices.

It is worth noting that undercutting is often present in these designs and therefore the contact ratio needs to be estimated from the form diameter of the gear, since standard formulae may not be applied. Once the form diameter is defined, the length of active segment $K_{1} K_{2}$ on the line of contact is obtained. In the end, the contact ratio is calculated by

$$
\mathrm{cr}=K_{1} K_{2} \cdot \frac{z}{\pi D_{\text {base }}}\left(>\mathrm{cr}_{\text {lim }}\right)
$$

where contact ratio limit $\mathrm{cr}_{\text {lim }}$ is set out in order to ensure continuous meshing.

Finally, the relief groove width on the path of contact $g_{\text {op }}$ is provided by

$$
g_{\mathrm{op}}=\zeta \cdot K_{1} K_{2} \cdot \cos \alpha_{\mathrm{op}},
$$

where $\zeta$ is a tuning parameter within 0 and 1 ; typically it stands within 0.6 and 1. Figure 3 illustrates the path of contact and the relief groove width. The purpose of the parameter $\zeta$ is to provide an entry point for further relief groove enhancements. In particular, it allows the estimation of the relief groove width compared to the gear geometry and dimensions, in case of single contact gearing. As mentioned in [18], an accurate evaluation of the relief groove dimension plays a key role in the proper functioning of the pump. Values of $\zeta$ close to 1 mean large relief groove width and, hence, high pressure peaks. On the contrary, thinner relief groove implies smoother pressure transitions, even though a reduction in terms of volumetric efficiency may occur. 


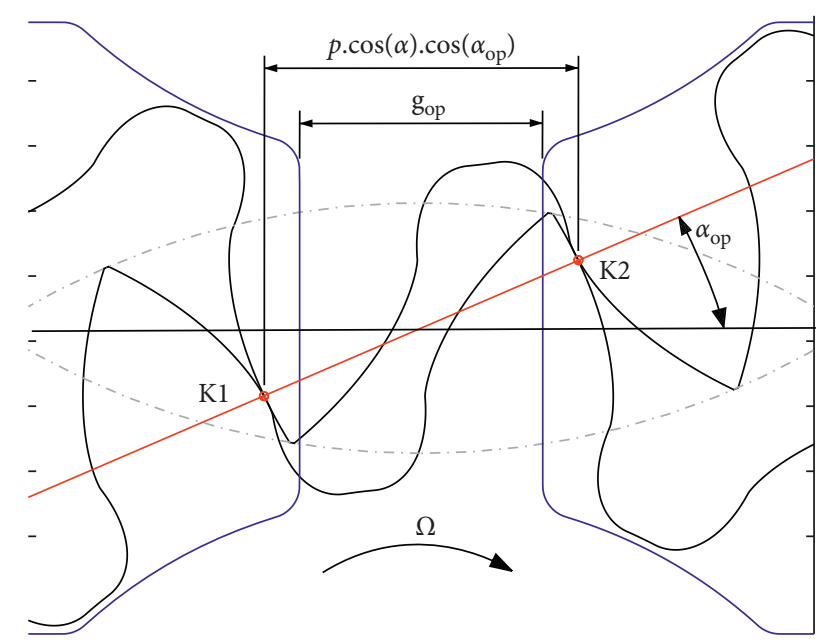

Figure 3: Path of contact and relief groove.

The third calculation phase consists in the improvement of the draft gear pair which is achieved by calibrating the input parameters. From the first draft design, even with slight parameters variations, the gear-pair characteristics may be enhanced. For gear pump application, the necessity to design nonstandard gears in order to achieve target performances allows assuming values of the module that is substantially different from the standard ones. As well as the other input parameters described, the module may be calibrated in order to achieve the improvement of the gearing. Its variation affects most of the input parameters; therefore, it should be the first tuned parameter in the improvement design phase. Later, other geometrical parameters may be further modified, such as operative center distance $I_{\text {op }}$ that directly reflects on the calibration of pump displacement. Alternatively, regulation of the face width $B$ provides equivalent results.

As a concluding step of the gear-pair design procedure, it is worth underlining that gears employed in volumetric machines often undergo a tooth flank grinding process with the purpose of improving surface quality and smoothness of gearing. For this reason, gear stock allowance is usually provided to the teeth flanks. The rack cutter designed in the former calculation phases has been adopted in order to achieve the final shape of the gear, without taking into account eventual grinding operations. With the purpose of considering manufacturability aspects, the design of the pregrinding rack cutter has been integrated into the procedure. From the choice of a certain gear stock allowance $\gamma$, the pregrinding tooth thickness at pitch circle $t_{\text {pitch }}{ }^{\prime}$ is calculated by equation (18):

$$
t_{\text {pitch }}^{\prime}=t_{\text {pitch }}+\gamma .
$$

By adapting equation (4), the updated profile shift $x^{\prime}$ is calculated by the following equation:

$$
x^{\prime}=\left(t_{\text {pitch }}^{\prime}-\frac{\pi m}{2}\right) \cdot \frac{1}{2 \tan \alpha},
$$

and the new rack cutter addendum $\operatorname{ad}_{T}^{\prime}$ is obtained:

$$
\operatorname{ad}_{T}^{\prime}=\frac{D_{\text {pitch }}-D_{r}}{2}+x^{\prime}
$$

2.2. Shaft and Bearings Design. Figure 4 shows a schematic view of loads and torques acting on a hypothetical driving shaft for an $\mathrm{N}$-stages pump. The estimation of the distributed pressure loads has been integrated according to the simplified formula presented in [19]:

$$
f_{i}=\frac{3}{4} \cdot \Delta p_{i} \cdot D_{\text {tip }, i}
$$

and, thus, total pressure torque is calculated as the sum of the pressure torques of the $\mathrm{N}$-stages. Within the frameworks of the current methodology, friction effects have been neglected from the calculations and each $i$-th stage pressure torque is calculated with reference to the formulation proposed in [19]:

$$
T=\sum_{i=1}^{N}\left(\Delta p_{i} \cdot\left(D_{t i p, i}^{2}-D_{\text {pitch }, \mathrm{op}, i}^{2}\right) \frac{B_{i}}{4}\right) .
$$

Shaft design concerns the driving shaft of the pump, since its total width is assumed to be higher than the driven one and subjected to external loads, such as forces due to motion transmission to the pump. It is worth noting that the number of pump stages, gears face width, support dimensions, and their number and layout are fundamental input data for the structural calculation. As part of the procedure, driving shaft has been outlined as a hyperstatic supported beam that can be structured with reference to the mentioned input data. The final outcome of this design phase is constituted by the minimum shaft diameter, which may be determined as follows:

$$
d_{\min }=\sqrt{[3]} \frac{1}{\sigma_{\mathrm{am}}} \sqrt{\left(\frac{32 \cdot \mathrm{Mb}_{\max }}{\pi}\right)^{2}+3 \cdot\left(\frac{16 \cdot T}{\pi}\right)^{2}},
$$

where $\sigma_{\mathrm{am}}$ is the admissible stress of shaft material and $\mathrm{Mb}_{\text {max }}$ is the maximum bending moment acting on the shaft.

The highest loaded support and working temperature combined to the lower speed of the driving shaft describe the worst-case scenario for the fluid-dynamic support. The design of the journal bearings, in particular of the radial clearance, is focused on the achievement of a satisfactory value of the minimum oil film under these boundary conditions. In the actual calculation phase, an iterative procedure for the design of the bearings has been implemented. Input parameters set is formed by oil density and kinematic viscosity at maximum working temperature $\rho_{T \max }, \mu_{T \max }$, minimum pump speed $n_{\min }$, maximum support load $P_{\max }$, shaft radius $r$, length of the bearing $l$, and radial clearance $\delta_{b}$.

Firstly, through the input parameters set, Sommerfeld number is calculated as

$$
S=\frac{\mu_{T \max } \cdot n}{P_{\max }}\left(\frac{r}{\delta_{b}}\right)^{2} .
$$




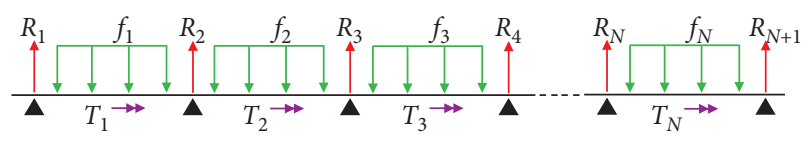

FIgURE 4: Driving shaft load framework.

The methodology has been implemented by assuming the diagrams in [20] as reference for the calculation of relative eccentricity $\chi$. The diagrams are specifically related to unitary bore diameter over length ratio bearings with singular axial groove. Thus, the eccentricity of the loaded floating shaft is obtained:

$$
e=\delta_{b} \cdot \chi
$$

Finally, the calculation of the minimum height of the oil film $\psi_{\text {min }}$ between shaft and bearing is expressed as

$$
\psi_{\min }=\delta_{b}(1-\chi)\left(>\psi_{\lim }\right)
$$

where the control parameter $\psi_{\text {lim }}$ is a lower limit established by good practices, with the purpose of ensuring the fluiddynamic support of the shaft.

2.3. Tip and Flank Clearance Design. The clearance between the gear tip circle and the pump housing has been determined by considering the dual effect produced by the tip clearance variation. Increasing clearance implies greater loss flows generated by the pressure difference between suction and pressure side and, consequently, the massive reduction of the volumetric efficiency. This sort of problem is particularly relevant when the machine works at high temperature and high pressure drop. On the other hand, decreasing tip clearance may cause the spread of the pressure of the oil trapped between the tip of the gears and the internal surface of the housing, which reduces the mechanical efficiency of the pump. The phenomenon is more evident, especially for low working temperatures. In both configurations, power losses affect the pump efficiency, and their behavior has been described in [15]. Assuming tip clearance $\delta_{h}$ as input parameter, power loss due to tip leakages is defined as

$$
W=\frac{\Delta P^{2} B^{4}}{12 \mu \cdot t_{\text {tip }}}\left(\frac{\delta_{h}}{B}\right)^{3}+\Omega_{\text {max }}^{2} \mu \cdot t_{\text {tip }}\left(\frac{D_{\text {tip }}}{2}\right)^{2}\left(\frac{B}{\delta_{h}}\right) .
$$

Since the procedure is oriented to pumps that work with low delivery pressure, balancing floating plates are not strictly required. Therefore, the flank clearance design procedure, implemented within this framework, reasonably follows the tip clearance design philosophy. It is worth noting that the results strictly depend on the oil temperature. For this reason, the calculation needs to be carried out at maximum and minimum allowable temperature values, in order to guarantee that the chosen clearance represents the best compromise throughout the entire range of working conditions.

\section{Assessment of the Design Procedure}

Based on the purpose of assessing the methodology described in Section 2, the procedure is applied to a case study by performing the design of a multistage gear pump. As part of the study, a three-stage configuration has been assumed providing one pressure stage, hereinafter named stage 1 , and two consecutive scavenge stages, hereinafter named stage 2 and stage 3, as depicted in Figure 5(a). Layout of the pump, working conditions, and target performances have been assumed as primary information and act as constraints data for the entire design process. Stage of the obtained machine is later analyzed by means of a CFD analysis in order to evaluate the effectiveness of the design. It is worth mentioning that the consistency of the proposed design procedure has been assessed also by applying it to existing gear pairs.

3.1. Design Procedure. Working conditions and target flow rates are summarized in Table 1, while the shaft layout coincides with the one reported in Figure 5(b), where loads and torques are also described. The cantilever beam represents the portion of the shaft where the driving torque is transmitted from the engine gearbox. Concentrated load $F$ arises from the torque transmission to the driving shaft. For gear transmissions, $F$ is equal to the meshing force. As reported in Table 1 , for the main stage, the theoretical volumetric efficiency has been assumed to be equal to $90 \%$.

The calculation process has been carried out beginning from the geometrical design of the gear pair. In particular, the gear pair has been calculated focusing on stage 1 target data. Input parameter set is listed in Table 2. Reported values are the outcomes of the calibration procedure of the input parameters, mentioned in Section 2.1. As it can be noticed, a negative profile shift has been provided ensuring the reduction of gearing center distance. On the other hand, these solutions induce undercut phenomena at the root of the teeth. Furthermore, it is clear that the module has been subjected to the calibration process and appears different from standard values, as it is customary in gear pumps.

While control parameter set is listed in Table 3, the most relevant output parameters are summarized in Table 4 . In addition to the gear-pair specifics, the other outcome of the geometrical design procedure is the $2 \mathrm{D}$ draws of the gears, depicted in Figure 3, which can be employed for the further numerical analyses. By means of the graphic feedback, parameter $\zeta$ has been calibrated to 0.8 with the purpose of ensuring proper leakage area during the volumes enclosure on the path of contact. By focusing on the results listed in Table 4, design displacement calculated to be $85.9 \mathrm{~cm}^{3}$ differs from the design value of $1.9 \%$. Furthermore, despite the fact that negative profile shift induces undercut, recognisable in Figure 3, contact ratio is acceptable.

Once the geometrical features of the gears are fully defined, loads and torques acting on the driving shaft can be calculated. By means of the resolution of the hyperstatic structure, the entire load layout is defined, together with the magnitude of the highest bearing reaction. After the 


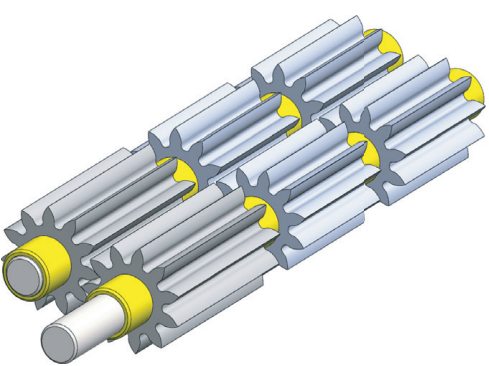

(a)

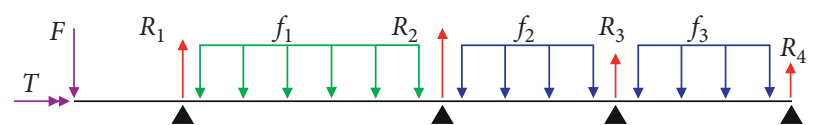

(b)

Figure 5: Driven and driving shaft of the case study pump (a). Driving shaft loads schematic (b).

TABLE 1: Working conditions and target flow rate.

\begin{tabular}{lcc}
\hline Description & Value & Unit \\
\hline Pump design speed & 3200 & $\mathrm{rpm}$ \\
Design temperature & 130 & ${ }^{\circ} \mathrm{C}$ \\
Stage 1 target flow rate & 252.0 & $\mathrm{dm}^{3} / \mathrm{min}$ \\
Stage 1 target displacement & 78.8 & $\mathrm{~cm}^{3}$ \\
Stages 2-3 target flow rate & 201.6 & $\mathrm{dm}^{3} / \mathrm{min}$ \\
Stages 2-3 target displacement & 63.0 & $\mathrm{~cm}^{3}$ \\
Theoretical volumetric efficiency & 0.90 & - \\
Stage 1 design displacement & 87.6 & $\mathrm{~cm}^{3}$ \\
Stage 1 design flow rate & 280.0 & $\mathrm{dm}^{3} / \mathrm{min}$ \\
\hline
\end{tabular}

TABLE 2: Input parameters for gear design.

\begin{tabular}{lcc}
\hline Description & Value & Unit \\
\hline Module & 3.640 & $\mathrm{Mm}$ \\
Teeth number & 11 & - \\
Rack cutter pressure angle & 24.0 & $\circ$ \\
Rack cutter tooth height & 9.83 & $\mathrm{Mm}$ \\
Rack cutter tooth addendum & 4.00 & $\mathrm{Mm}$ \\
Rack cutter tip fillet radius & 0.73 & $\mathrm{~mm}$ \\
Profile shift & -0.535 & $\mathrm{~mm}$ \\
Tip diameter & 48.50 & $\mathrm{~mm}$ \\
Operative center distance & 40.80 & $\mathrm{~mm}$ \\
Pressure gear face width & 84.00 & $\mathrm{~mm}$ \\
Scavenge gear face width & 65.00 & $\mathrm{~mm}$ \\
\hline
\end{tabular}

TABle 3: Control parameters.

\begin{tabular}{lcc}
\hline Description & Value & Unit \\
\hline Error on target displacement & $+/-2$ & $\%$ \\
Tip thickness limit & 0.10 & $\mathrm{~mm}$ \\
Gearing total width limit & 90.0 & $\mathrm{~mm}$ \\
Backlash minimum limit & 1.00 & $\mathrm{~mm}$ \\
Contact ratio lower limit & 1.20 & - \\
\hline
\end{tabular}

calculation of the stress scheme of the shaft, the minimum resistant diameter has been calculated on the section subjected to the maximum bending moment. In addition to the normal stress, shear stress due to pressure torque has been taken into account for the calculation. The complete set of input data and the results of load calculation are listed in Table 5.

Following the methodology illustrated in Section 2.3, the design of the bearings has been carried out for the worst-case scenario in order to ensure the proper functioning in every
TABle 4: Output parameters of gear design.

\begin{tabular}{lcc}
\hline Description & Value & Unit \\
\hline Tooth thickness & 5.24 & $\mathrm{~mm}$ \\
Stock allowance & 0.30 & $\mathrm{~mm}$ \\
Pregrinding rack cutter ad. & 4.42 & $\mathrm{~mm}$ \\
Pregrinding profile shift & -0.20 & $\mathrm{~mm}$ \\
Root diameter & 30.8 & $\mathrm{~mm}$ \\
Form diameter & 36.7 & $\mathrm{~mm}$ \\
Operative pressure angle & 26.3 & $\circ$ \\
Relief groove height ratio & 0.80 & - \\
Relief groove height & 7.50 & $\mathrm{~mm}$ \\
Pump displacement & 85.9 & $\mathrm{~cm}$ \\
Gearing total width & 89.3 & $\mathrm{~mm}$ \\
Backlash & 1.52 & $\mathrm{~mm}$ \\
Root clearance & 1.07 & $\mathrm{~mm}$ \\
Tip circle tooth thickness & 0.15 & $\mathrm{~mm}$ \\
Contact ratio & 1.32 & $\mathrm{~mm}$ \\
\hline
\end{tabular}

working condition. The most loaded support is located between pressure and scavenge stage. The first part of Table 6 resumes the input data assumed for the bearing calculation, whereas the results of the bearing calculation are listed in the second part.

Similarly, the worst-case scenario related to power loss calculation has been taken into account for the design of the nominal radial gap between gears and casing. Input data and the results of the current calculation step are summarized in Table 7. Tip clearance value has been designed by means of the calculation of the power loss for the maximum pressure drop at minimum and maximum working temperature. The target value of the tip clearance ensures limited mechanical losses for low temperature and limited volumetric losses at high temperature, as described in Section 2.3.

3.2. CFD Analysis Setup. In the present work, the designed pump has been tested by a CFD analysis with the purpose of validating the design procedure. Since the gear pump operation is affected by the engagement process and the clearances between wheels and casing, the CFD analysis has been carried out by a fully three-dimensional transient simulation with the mesh morphing strategy. This dynamic approach accounts for the pressure pulsation and cavitation phenomenon due to the pump operation (i.e., wheel engagement) and it has been carried out by the software PumpLinx 4.6 .4 by Simerics Inc. ${ }^{\circledR}$ (Bellevue, WA, USA). As 
TABle 5: Loads calculation.

\begin{tabular}{lcc}
\hline Description & Value & Unit \\
\hline Stage 1 design pressure drop & 4.0 & bar \\
Stages 2-3 design pressure drop & 2.0 & bar \\
Stage 1 pressure load & 11640.0 & $\mathrm{~N} / \mathrm{m}$ \\
Stages 2-3 pressure load & 5563.2 & $\mathrm{~N} / \mathrm{m}$ \\
Total torque & 10.2 & $\mathrm{~N} \mathrm{~m}$ \\
Shaft diameter & 21.0 & $\mathrm{~mm}$ \\
\hline
\end{tabular}

TABLE 6: Input and output data for journal bearing calculation.

\begin{tabular}{llcc}
\hline & Description & Value & Unit \\
\hline \multirow{4}{*}{ Input } & Minimum pump speed & 1300 & $\mathrm{rpm}$ \\
& Maximum temperature & 130 & ${ }^{\circ} \mathrm{C}$ \\
& Dynamic viscosity & 6.70 & $\mathrm{mPa} \mathrm{s}$ \\
& Maximum support load & 1044.7 & $\mathrm{~N}$ \\
\hline \multirow{5}{*}{ Output } & Bearing length & 21.0 & $\mathrm{~mm}$ \\
& Nominal radial clearance & 0.016 & $\mathrm{~mm}$ \\
& Sommerfeld number & 0.1661 & - \\
& Relative eccentricity & 0.5406 & - \\
& Maximum eccentricity & 0.0086 & $\mathrm{~mm}$ \\
& Minimum oil film & 0.0074 & $\mathrm{~mm}$ \\
\hline
\end{tabular}

TABLE 7: Input and output parameters for tip clearance calculation.

\begin{tabular}{cccc}
\hline & Description & Value & Unit \\
\hline \multirow{6}{*}{ Input } & Maximum pump speed & 4480 & $\mathrm{rpm}$ \\
& Stage 1 max. pressure drop & 10 & bar \\
& Minimum temperature & -15 & ${ }^{\circ} \mathrm{C}$ \\
& Maximum temperature & 130 & ${ }^{\circ} \mathrm{C}$ \\
& Dynamic visc. $\left(T_{\min }\right)$ & 6938.9 & $\mathrm{mPa} \mathrm{s}$ \\
& Dynamic visc. $\left(T_{\max }\right)$ & 6.71 & $\mathrm{mPa} \mathrm{s}$ \\
& Tip circle tooth thick. & 0.15 & $\mathrm{~mm}$ \\
& Tip diameter & 48.5 & $\mathrm{~mm}$ \\
Output & Pressure gear face width & 84.0 & $\mathrm{~mm}$ \\
& Nominal tip clearance & 0.063 & $\mathrm{~mm}$ \\
& Power loss $\left(T_{\min }\right)$ & 0.181 & $\mathrm{~kW}$ \\
& Power loss $\left(T_{\max }\right)$ & 1.742 & $\mathrm{~kW}$ \\
\hline
\end{tabular}

proven in the literature $[16,17]$, this software is able to catch the transient phenomena as well as the cavitation issues, showing a good agreement with the experimental results.

The computational model used for the analysis is reported in Figure 6. It comprises the entire pump casing equipped with the clearances (which are responsible for the leakages at tooth flank-pump casing sides and tooth head-pump casing periphery) and the inlet and outlet ports, since the pump performance, especially the volumetric efficiency, is strongly affected by these. The internal volume of the gear pump has been discretized through a body-fitted curvilinear mesh type able to account for the wheel rotation and engagement: by the morphing mesh algorithms, the shape of the gear pump domain is accommodated by the dynamic mesh at each time step. The evaluation of the grid sensitivity and the associated errors was performed. The calculation is based on Richardson extrapolation and it was performed by considering the flow rate delivered by the pump. For subsequent meshes, a constant value of grid refinement factor equal to 1.5 (applied to both stationary and moving domains) was imposed. From this analysis, the extrapolated relative error was equal to $1.9 \%$ and the Grid Convergence Index (GCI) was equal to $2.1 \%$. This structured mesh is made by about 2 million elements and it is connected to the suction and discharge ports through sliding interfaces able to couple the stationary and rotating domains. The pump ports are discretized using a Cartesian grid (binary-tree mesh type) refined in the proximity of the sliding mesh interfaces. The axial gaps are equipped with five layers of hexahedral elements and coupled with the rotating domain through a sling interface. The stationary domain is composed of about 1 million elements. Since no experimental data are available, the computational analysis accuracy was set up with the reference of the models reported in $[16,17]$.

The CFD analysis has been carried out by considering three different pump speeds equal to 1.0, 1.2, and 1.4 of the design speed $\Omega$ and for a set of discharge pressure conditions up to 11 bar. In particular, the computational model was used for mapping the pump performance for different rotational speeds and different discharge pressure values. The static inlet pressure was kept constant: the pump blows the oil from a tank characterized by a constant oil level that corresponds to a static pressure of 1.05 bar. Differently, the discharge pressure was progressively increased for discovering the pump performance at different rotational speeds. For turbulence modeling, the $\mathrm{k}-\epsilon$ turbulence model was adopted. The cavitation phenomenon is modeled employing the equilibrium dissolve gas model implemented in PumpLinx 4.6.4 [21]. Imposing the 5\% in volume of air completely dissolved at the inlet section of the pump.

\section{Results}

In the present section, the features of the methodology are assessed by evaluating the results of the CFD analysis performed for the pressure stage which has been taken as reference for the validation. The reason lies in the fact that the relevance of the scavenge stages fluid-dynamic behavior is incidental. The aim of these stages is to convey the oil from the sump to the oil tank providing extremely low pressurization to the oil. On the contrary, pressure stage is devoted to displacing the oil to the entire engine lubrication system, reaching high oil pressure values. It is therefore subjected to the leakage phenomena and efficiency reduction, described within Section 2, which need to be monitored. Within this context, the CFD model is used as a virtual test bench to investigate several operating conditions and map the pump efficiency. The mapping process comprises four pressure drop values calculated as the pressure difference between delivery and suction ports and three rotational speeds, correspondent to the design value $\left(\left(\Omega_{\mathrm{op}} / \Omega\right)=1\right)$ and two off-design values $\left(\left(\Omega_{\mathrm{op}} / \Omega\right)=1.2\right.$ and $\left.\left(\Omega_{\mathrm{op}} / \Omega\right)=1.4\right)$. For each pump speed, the theoretical flow rate is calculated as the multiplication of the pump displacement times the pump speed. Thus, the efficiency is calculated as the ratio of the CFD resultant flow rate $Q_{\text {op }}$ with respect to the theoretical flow rate $Q$. 


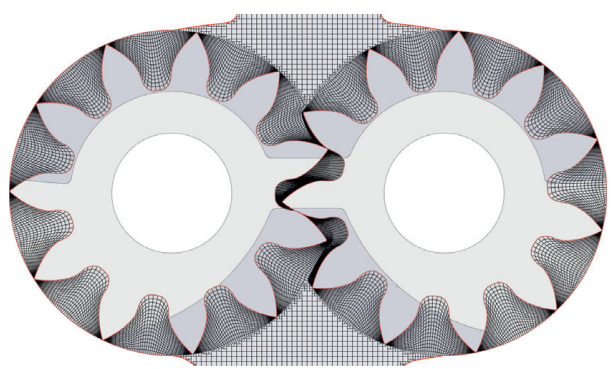

Figure 6: Planar view of the computational model, body-fitted curvilinear mesh.

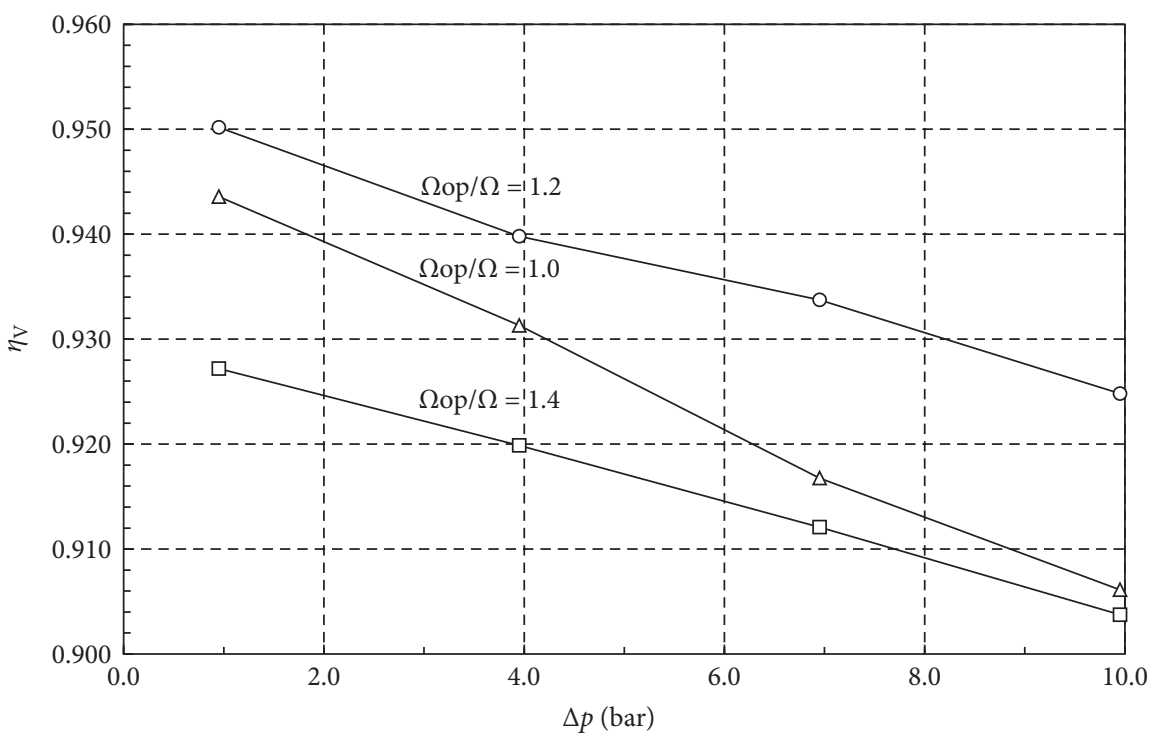

FIGURE 7: CFD analysis efficiency map.

Figure 7 shows the efficiency map based on the delivery pressure as a function of the pump rotational speed. The pump performance is aligned with design constraints and predictions. Furthermore, the volumetric efficiency is always higher than the theoretical value assumed in the early phase of the design procedure listed in Table 1. It is worth noting that, at design condition $\left(\left(\Omega_{\mathrm{op}} / \Omega\right)=1, \Delta p=4.0 \mathrm{bar}\right)$, the volumetric efficiency has been calculated to be $93.4 \%$. As proven in [22], the effect of leakages through the designed clearances increases linearly with the delivery pressure increment. In particular, a higher-pressure condition imposes a substantially equal reduction of the volumetric efficiency for the three tested pump speeds.

Table 8 resumes the calculated flow rates from the CFD analyses and it allows performing a direct confrontation with the target flow rate at different pump speed. From the analysis of the results, flow rate has been calculated to be 256 $\mathrm{dm}^{3} /$ min at design working condition, leading to a deviation of $1.6 \%$ with respect to the target flow rate, which is equal to $252 \mathrm{dm}^{3} / \mathrm{min}$. The scatter between calculated and target flow rate values stands at lower than $4.0 \%$ in every working point.

The results highlight that the analytical procedure for the design of the gears and clearances is trustworthy and robust and it may be adapted for the design of a wide family of multistage gear pumps.
The structure of the design procedure gives the user the possibility to tailor the value of some geometrical parameters. As described in Section 2, the iterative calculation scheme is based on the respect of geometrical constraints that lead to designing a pump that elaborates a proper flow rate with good volumetric efficiency. On the other hand, the procedure does not allow identifying a priori the implications on the pressure field correlated to the geometrical parameters' calibration. The choice of radial gap value between gear and housing or relief groove width, the shape of the resultant tooth flank, and the backlash between the inactive flanks are geometrical features that together come from the iterative design procedure and directly affect the pump behavior. Therefore, during this design step, the CFD results could be useful for analyzing the pressure-flow field.

Figure 8 reports a contour plot of the static pressure field on the plane of motion of the gears, centered with respect to their face width. Due to the engagement process, a certain volume of oil is enclosed at the discharge side and released towards the inlet side (low-pressure port). This implies that an instantaneous pressure variation (expansion) occurs generating pressure pulsation. According to this phenomenon, the oil entrapment within the meshing zone produces pressure peaks up to 20 bar. This behavior, despite being not desirable, is well known to affect external gear machines and it may be accepted 
TABLE 8: Comparison between calculated and target flow rates.

\begin{tabular}{ccccc}
\hline & Pressure drop (bar) & Target flow rate $\left(\mathrm{dm}^{3} / \mathrm{min}\right)$ & Calculated flow rate $\left(\mathrm{dm}^{3} / \mathrm{min}\right)$ & Deviation $(\%)$ \\
\hline & 1.0 & 252.0 & 259.4 & 256.0 \\
$\left(\Omega_{\mathrm{op}} / \Omega\right)=1.0$ & 4.0 & 252.0 & 252.0 & +2.9 \\
& 7.0 & 252.0 & 249.1 & +1.6 \\
& 10.0 & 252.0 & 313.4 & +0.0 \\
$\left(\Omega_{\mathrm{op}} / \Omega\right)=1.2$ & 1.0 & 302.4 & 310.0 & +1.2 \\
& 4.0 & 302.4 & 308.0 & +3.6 \\
& 7.0 & 302.4 & 305.1 & +2.5 \\
$\left(\Omega_{\mathrm{op}} / \Omega\right)=1.4$ & 10.0 & 302.4 & 356.8 & +0.9 \\
& 1.0 & 384.8 & 354.0 & +1.1 \\
& 4.0 & 384.8 & 351.0 & -0.3 \\
$\mathrm{v}$
\end{tabular}

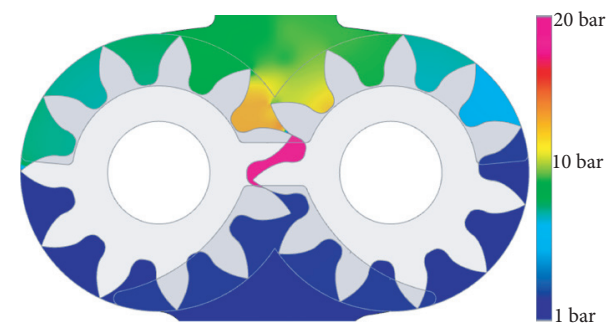

Figure 8: Pressure field in the middle section of the pump $\left(\left(\Omega_{\mathrm{op}} / \Omega\right)=1.2\right.$ and $\Delta_{P}=9.95$ bar $)$.

as long as pressure peak values do not produce clear detrimental effects on the pump. Pressure fluctuations and, in turn, vibration and noise issues can be analyzed in the early design phase employing CFD dynamic model. As a matter of fact, the calculation procedure linked to CFD analysis acts as a key tool not only for the primary design phase but also for the improvement phase of a gear pump. By the analysis of the results of the CFD simulation, the designer is able to improve the pump design properly recalibrating the input parameter sets of the procedure. The updated output parameter sets could be easily implemented in a new pump layout. For example, if the CFD highlights pressure peaks in the meshing zone, it would be a good choice for the users to investigate the relief groove height and calibrate the relief groove ratio parameter within the procedure input parameter list. New design and higher rotational speed (typically off-design conditions) as well as particular operating conditions (e.g., temperature variation of the oil) can be analyzed by means of virtual tools, giving the possibility to improve the design, reducing the number of prototypes, and shrinking the trial-and-error approaches.

\section{Conclusions}

The present work describes an analytical procedure for the design of a multistage gear pump that integrates the geometrical design of the gears, the driving shaft structural analysis, and the internal clearances design.

The main purpose of the work is the development of a robust procedure that leads to designing the main components of a gear pump, achieving the target performances, by means of a reasonable number of input parameters. The core of the activity is the development of the geometrical design procedure for the spur gears which has been proven to be robust and flexible. Furthermore, the generation of the $2 \mathrm{D}$ tooth profile of the gear has been integrated in the procedure. The addition of a case study has allowed highlighting the potential of the iterative procedure by the design of the main features, beginning from the working constraints. On the resultant pump, a CFD analysis has been performed to provide the validation of the design procedure. The analysis has been carried out at design working condition, assuming nominal clearances between pump components. The results have confirmed the reliability of the implemented methodology and a satisfactory agreement in terms of volumetric efficiency has been reached between the theoretical values and the measured one.

As final remarks, the flexible structure of the iterative procedure allows tailoring it for the development of a wide variety of multistage gear pumps, pursuing the scope of the presented work.

\section{Abbreviations}

Greek letters

$\alpha$ : Contact angle

$\gamma: \quad$ Gear stock allowance

$\Delta P: \quad$ Pressure drop between delivery and suction side

$\delta: \quad$ Clearance

$\eta_{v}: \quad$ Volumetric efficiency

$\zeta$ : $\quad$ Relief groove width ratio

$\mu$ : $\quad$ Oil viscosity

$\rho: \quad$ Oil density

$\sigma: \quad$ Normal stress

$\chi$ : $\quad$ Relative eccentricity

$\psi: \quad$ Height of the oil film

$\Omega$ : $\quad$ Angular speed

ad: Addendum

B: $\quad$ Face width

b: Backlash

Cc: Pump displacement

cr: $\quad$ Contact ratio

D: Gear circles diameter

d: $\quad$ Shaft diameter

e: Eccentricity of the shaft

f: Distributed pressure load

g: Height of the relief groove 
h: Tooth height

I: $\quad$ Center distance.

$K_{1} K_{2}$ : Active contact segment

$\mathrm{l}$ : Bearing length

$\mathrm{Mb}$ : Bending moment

m: Module

n: Rotational speed

P: Support load

Q: $\quad$ Flow rate

r: $\quad$ Shaft radius

S: $\quad$ Sommerfeld number

T: Torque

t: $\quad$ Tooth thickness

W: Power loss

w: Gearing total width

$\mathrm{x}$ : $\quad$ Profile shift

z: Number of teeth of the gear.

': $\quad$ Superscript referring to pregrinding data

*: $\quad$ Superscript referring to assumed data

am: Subscript referring to admissible data

b: Subscript referring to bearing data

base: Subscript referring to base circle

des: Subscript referring to design condition

h: $\quad$ Subscript referring to housing data

i: $\quad$ Subscript referring to $i$-th stage of the pump

lim: Subscript referring to limit condition

min: Subscript referring to minimum condition

max: Subscript referring to maximum condition

op: Subscript referring to operating condition

pitch: Subscript referring to pitch circle

$r$ : Subscript referring to root circle

T: $\quad$ Subscript referring to tool data

tip: Subscript referring to tip circle.

\section{Data Availability}

The geometrical data used to support the findings of this study are currently under embargo while the research findings are commercialized. Requests for data will be considered by the corresponding author.

\section{Conflicts of Interest}

The authors declare that they have no conflicts of interest.

\section{References}

[1] S. Mancó and N. Nervegna, "Pressure transients in an external gear hydraulic pump," Fluid Power, vol. 1993, no. 2, pp. 221-227, 1993.

[2] S. Mancò and N. Nervegna, "Simulation of an external gear pump and experimental verification," in Proceedings of the JHPS International Symposium on Fluid Power, Tokyo, Japan, March 1989.

[3] E. Mucchi, G. Dalpiaz, and A. F. Del Rincòn, "Elastodynamic analysis of a gear pump. Part I: pressure distribution and gear eccentricity," Mechanical Systems and Signal Processing, vol. 24, no. 7, pp. 2160-2179, 2010.

[4] E. Mucchi, G. Dalpiaz, and A. Rivola, "Elastodynamic analysis of a gear pump. Part II: meshing phenomena and simulation results," Mechanical Systems and Signal Processing, vol. 24, no. 7, pp. 2180-2197, 2010.

[5] A. Vacca and M. Guidetti, "Modelling and experimental validation of external spur gear machines for fluid power applications," Simulation Modelling Practice and Theory, vol. 19, no. 9, pp. 2007-2031, 2011.

[6] B. Zardin, E. Natali, and M. Borghi, "Evaluation of the hydro-mechanical efficiency of external gear pumps," Energies, vol. 12, no. 13, 2017.

[7] F. Rituraj, A. Vacca, and A. Morselli, "Modeling of manufacturing errors in external gear machines and experimental validation," Mechanism and Machine Theory, vol. 140, pp. 457-478, 2019.

[8] M. Battarra and E. Mucchi, "On the assessment of lumped parameter models for gear pump performance prediction," Simulation Modelling Practice and Theory, vol. 99, pp. 1-22, 2020.

[9] S. Mo, Z. Yue, Z. Feng, L. Shi, Z. Zou, and H. Dang, "Analytical investigation on load-sharing characteristics for multi-power face gear split flow system," Proceedings of the Institution of Mechanical Engineers, Part C: Journal of Mechanical Engineering Science, vol. 234, no. 2, pp. 676-692, 2020.

[10] M. Shuai, Z. Ting, J. Guo-guang, C. Xiao-lin, and G. Han-jun, "Analytical investigation on load sharing characteristics of herringbone planetary gear train with flexible support and floating sun gear," Mechanism and Machine Theory, vol. 144, 2020.

[11] M. Battarra and E. Mucchi, "A method for variable pressure load estimation in spur and helical gear pumps," Mechanical Systems and Signal Processing, vol. 76-77, pp. 265-282, 2016.

[12] M. Battarra, E. Mucchi, and G. Dalpiaz, A Model for the Estimation of Pressure Ripple in Tandem Gear PumpsASME IDETC/CIE, 2015.

[13] J. R. Colbourne, The Geometry of Involute Gears, SpringerVerlag, New York, NY, USA, 1987.

[14] C. Bonacini, "Sulla portata delle pompe ad ingranaggi," L'Ingegnere, vol. 9, no. 1, pp. 1-8, 1961.

[15] W. E. Wilson, "Clearance design in positive displacement pumps," Machine Design, vol. 1, no. 1, pp. 127-130, 1963.

[16] N. Casari, E. Fadiga, M. Pinelli, S. Randi, and A. Suman, "Pressure pulsation and cavitation phenomena in a microORC system," Energies, vol. 12, no. 11, 2019.

[17] U. Stuppioni, A. Suman, M. Pinelli, and A. Blum, "Computational fluid dynamics modeling of gaseous cavitation in lubricating vane pumps: an approach based on dimensional analysis," Journal of Fluid Engineering, vol. 142, no. 7, 17 pages, 2020.

[18] E. Mucchi, G. Dalpiaz, and A. Rivola, "Dynamic behavior of gear pumps: effect of variations in operational and design parameters," Meccanica, vol. 46, no. 6, pp. 1191-1212, 2011.

[19] J. Ivantysyn and M. Ivantysynova, Hydrostatic Pumps and Motors Principles, Design, Performance, Modeling, Analysis, Control and Testing, Tech Book International, New Delhi, India, 2003.

[20] T. Someya, Journal Bearing Databook, Springer-Verlag, Berlin, Germany, 1989.

[21] Simerics Inc, PumpLinx's User Manual-V 4.6.4, Simerics Inc., Bellevue, WA, USA, 2018.

[22] E. Mucchi, M. Battarra, A. Suman, M. Pinelli, and G. Dalpiaz, Combining Lumped Parameter Modelling and CFD Analysis for the Pressure Ripple Estimation of Tandem Gear Pumps, Elsevier Inc., Amsterdam, Netherlands, 2019. 